\title{
Effect of Commercially Available and Experimental Potassium Oxalate-Based Dentin Desensitizing Agents in Dentin Permeability: Influence of Time and Filtration System
}

\author{
Sérgio Lima SANTIAGO ${ }^{1}$ \\ José Carlos PEREIRA ${ }^{2}$ \\ Ana Christina Bonato Figueiredo MARTINELI ${ }^{3}$ \\ ${ }^{1}$ Department of Restorative Dentistry, School of Pharmacy, Dentistry and Nursing, \\ Federal University of Ceará, Fortaleza, CE, Brazil \\ ${ }^{2}$ Department of Restorative Dentistry and Endodontics, School of Dentistry of Bauru, \\ University of São Paulo, Bauru, SP, Brazil \\ ${ }^{3}$ Private Practice, Marília, SP, Brazil
}

\begin{abstract}
This study evaluated the influence of time after application of oxalate solutions in reducing dentin hydraulic conductance. Fifty dentin discs were obtained from extracted human third molars and assigned to 5 groups $(n=10)$, according to the desensitizing agent used: Group I: OxaGel; Group II: experimental agent DD-1: Group III: experimental agent DD-2. In Groups IV and V, a placebo gel and deionized water were used as control, respectively. The agents were applied for 3 min, washed out and the hydraulic conductance was measured immediately and at 5-, 15- and 30-min intervals, and after acid etching. Data were analyzed statistically by two-way ANOVA and Duncan's test at 5\% significance level. Groups I, II and III did not differ significantly from each other in any of the time intervals $(\mathrm{p}>0.05)$. Likewise, Groups IV and V were statistically similar to each other $(\mathrm{p}>0.05)$. The active agents reduced significantly dentin permeability in comparison to control groups $(\mathrm{p}<0.05)$. Dentin permeability measured in vitro decreased significantly with time regardless of the agent applied (either active or control agents). The results of Group V, in which no dentin desensitizing agent was employed, indicates that the assessment of dentin permeability by this method must be interpreted with caution.
\end{abstract}

Key Words: dentin, dentin permeability, dentin sensitivity.

\section{INTRODUCTION}

Dentin hypersensitivity is an exaggerated response to a sensory stimulus that usually causes no response in a normal, healthy tooth and is associated with dentin exposure to the oral environment. This exposure can result from loss of enamel by abrasion, erosion, abfraction or denudation of root surface as a result of gingival recession or periodontal treatments (1). Dentin hypersensitivity is generally reported by the patient after experiencing a sharp pain caused by one of several different stimuli (2).

Several different empirical treatments have been used in the past to decrease or eliminate dentin sensitiv- ity. None of them, however, works predictably. The major problem regarding the development of dentin desensitizing agents is that the mechanism of dentin sensitivity is not yet clearly understood (3). The most widely accepted hypothesis about how the stimuli influence nerve fibers is the Brännström's hydrodynamic theory. This theory states that there is fluid within the dentinal tubules that moves in either inward or outward direction when stimuli are applied, which stimulates the nerve endings at the pulp/dentin interface, resulting in generation of pain impulses (4).

Historically, several desensitizing agents have been used for treating this problem, including, hot oil, arsenic, silver nitrate and formaldehyde. Currently, 
other ways of treatment have emerged such as oxalate solutions, which have shown significant effectiveness in reducing dentin permeability and pain. These agents precipitate calcium oxalate crystals that occlude patent exposed dentinal tubules $(2,4)$. These crystals reduce fluid movement within dentin and, consequently, reduce dentin sensibility. This study evaluated in vitro the influence of time after application of oxalate solutions in reducing dentin hydraulic conductance, using a placebo gel and deionized water as controls.

\section{MATERIAL AND METHODS}

Fifty extracted human unerupted caries-free third molars were used in this study. Teeth were obtained from adult patients of both sexes aged 18 to 28 years. Immediately after extraction, teeth were stored in phosphate buffered saline (PBS) containing $0.2 \%$ sodium azide to inhibit microbial growth for 6 months at most.

Using a water-cooled low-speed diamond disc (Extec Division Excel Technologies Inc., Enfield, CT, USA) mounted in a sectioning machine (Extec Division Excel Technologies Inc.), the teeth were cut perpendicular to the long axis of the root at two sites: just below the apical limit of the occlusal dentinoenamel junction and within the coronal limit of the pulp chamber (Fig. 1). Dentin discs with a periphery of enamel were obtained (5). The discs were reduced in thickness on both the pulpal and enamel sides with wet 600 -grit silicon carbide paper (3M do Brasil, Sumaré, SP, Brazil) until reaching $0.92 \pm 0.08 \mathrm{~mm}$ in thickness, as measured by a micrometer accurate to $0.01 \mathrm{~mm}$. Disc surfaces were

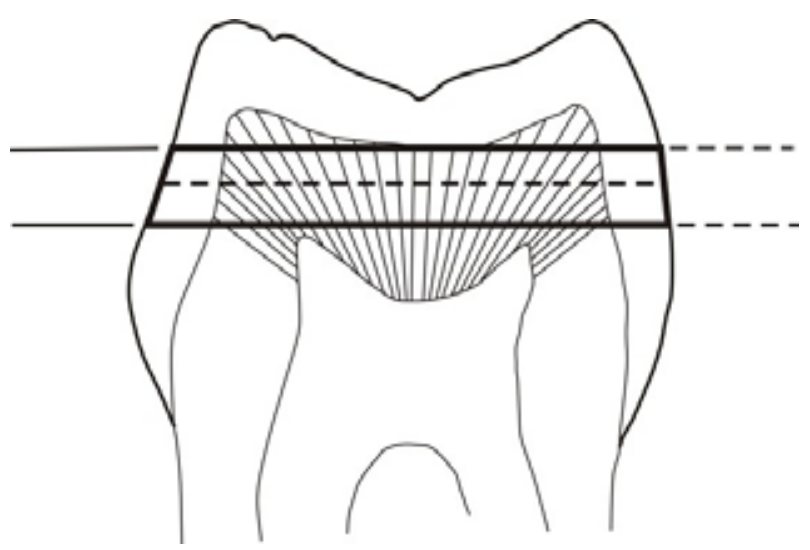

Figure 1. Scheme of tooth sectioning to obtain the dentin disc. polished with wet 1500-grit silicone-oxide sand paper (3M do Brasil) and examined under stereomicroscope at X40 magnification (Meiji Techno Co. Ltda., Tokyo, Japan) for the presence of enamel and/or pulp horns. Polishing was repeated until all traces of enamel and pulp horns were eliminated.

The 50 dentin discs were randomly assigned to 5 groups $(\mathrm{n}=10)$ according to the desensitizing agent: Group I: OxaGel (3\% monohydrate potassium oxalate solution $\mathrm{pH} 4$ plus carboxymethylcellulose gel; Art-Dent Ind. e Com. de Produtos Odontológicos Ltda, Araraquara, SP, Brazil); Group II: DD-1 experimental agent (dentin desensitizing-1; 6\% monohydrate potassium oxalate solution $\mathrm{pH} 4$ plus carboxymethylcellulose gel); Group III: DD-2 experimental agent (3\% monohydrate potassium oxalate solution $\mathrm{pH} 2.5$ plus carboxypolymethylene (carbopol) gel; Group IV: placebo (minus-active; carboxymethylcellulose gel); Group V: deionized water. DD-1 and DD-2 were developed by the Prof. José Carlos Pereira at the School of Dentistry of Bauru.

Each dentin disc was placed in a split-chamber device that allowed the standardization of exposed dentin area by using pairs of rubber "O" rings that provided 0.178 or $0.282 \mathrm{~cm}^{2}$ of available surface area for filtration of deionized water. These areas depended on the size of dentin discs. Hydrostatic pressure of $703.1 \mathrm{cmH}_{2} \mathrm{O}$ was applied and the rate of fluid movement across dentin (filtration) was measured by following the progress of a small air bubble in a micropipette lying on top of a millimeter scale (6) (Fig. 2).

Hydraulic conductance (Lp) quantifies the bulk fluid movement occurring through dentin at a hydro-

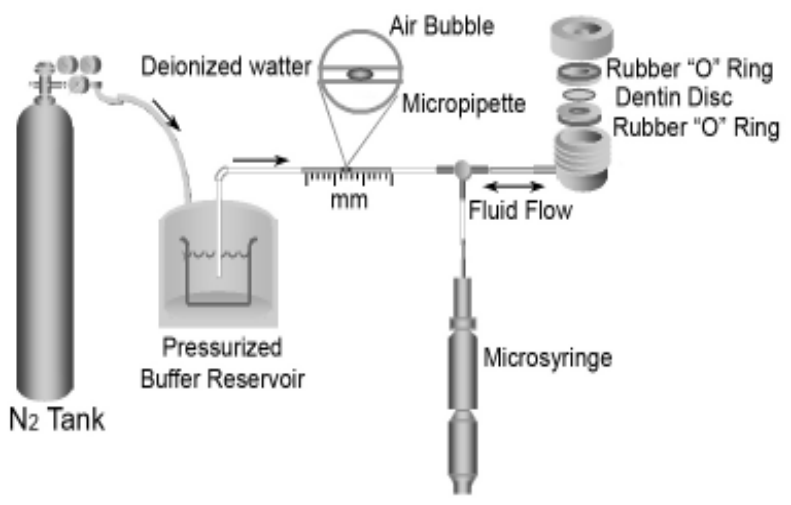

Figure 2. Scheme of the split-chamber device used to measure dentin hydraulic conductance [adapted from Pashley and Galloway, 1985 (6)]. 
static pressure gradient. The measurement of dentin hydraulic conductance provides a convenient, quantitative measurement of dentin permeability. Two basic factors were taken into account before testing the effect of the agents on dentin hydraulic conductance. First, it is known that the presence of smear layer is the most effective condition to obstruct the dentinal tubules and reduce liquid flow through the dentin. Second, demineralization allows greater dentin permeability. Therefore, the hydraulic conductance was measured initially in the presence of smear layer to assess minimum permeability and subsequently the dentin discs were etched in order to establish maximum permeability values of each specimen individually. Maximum permeability values were considered $100 \%$ of each specimen's filtration. The other values, including the effects of experimental materials and smear layer were calculated as a proportion of $100 \%$ permeability. Once maximum permeability was determined, the desensitizing agents were applied to dentin disc surface for $3 \mathrm{~min}$, and thoroughly rinsed with deionized water. Filtration was immediately measured, this value being considered the immediate hydraulic conductance. Measurements were repeated 4 more times at each pre-established interval, namely 5 , 15 and $30 \mathrm{~min}$ after initial measurement.

Means $( \pm \mathrm{SD}$ ) were obtained from the 4 measurements made for each condition and the percentage relative to maximum permeability was calculated. This percentage indicated disc permeability in response to the agents applied and was calculated using the following equation: $\mathrm{LP}=\mathrm{Q} / \mathrm{P}(\mathrm{SA})$, where $\mathrm{Lp}=$ hydraulic conductance of dentin in $\mu \mathrm{L} \cdot \mathrm{cm}^{-2} \cdot \mathrm{min}^{-1} \cdot \mathrm{cmH}_{2} \mathrm{O} ; \mathrm{Q}=$ filtration rate in $\mu \mathrm{L}$. $\min ^{-1} ; \mathrm{P}=$ hydrostatic pressure across dentin in $\mathrm{cmH}_{2} \mathrm{O} ; \mathrm{SA}=$ surface area in $\mathrm{cm}^{2}$.
Because the micropipette has constant bore diameter, dividing the pipette volume by its length gives a proportionality constant that converts linear displacement into volume displacement within dentin (5).

After the measurements of the 30-min interval, the treated surface of the discs was conditioned with citric acid at $6 \% \mathrm{pH} 2$ for $1 \mathrm{~min}$ in order to evaluate the resistance of possible occlusive effects of the tested materials to a recurrent acid medium and is herein referred to as acid challenge. This sequence of procedures was repeated to all experimental groups. In Group $\mathrm{V}$, where no agent was used, maximum and minimum permeability were recorded, allowing the simple filtration of deionized water throughout the established time interval. These values were also recorded for further comparison to the other groups.

Data were analyzed statistically by two-way ANOVA at 5\% significance level using SPSS 10.0 statistical software for Windows (SPSS 10.0 Inc., Chicago, IL, USA). Significant differences were found between materials, conditions and interaction materials $\mathrm{X}$ conditions. Individual comparisons by Duncan's test at $5 \%$ significance level identified the differences.

\section{RESULTS} Table 1 .

Hydraulic conductance means (\%) are shown on

No statistically significant differences $(p>0.05)$ were observed among OxaGel, DD-1 and DD-2 in any of the tested conditions (immediate, 5, 15, $30 \mathrm{~min}$ and after acid challenge). Likewise, placebo and deionized water did not differ significantly to each other ( $p>0.05$ ). Nevertheless, statistically significant differences

Table 1. Means $(\%)$ of hydraulic conductance $( \pm \mathrm{SD})$ for each material $(\mathrm{n}=10)$ as a function of time and after acid challenge as well as minimum hydraulic conductance.

\begin{tabular}{lllcccc}
\hline Agent & Minimum & \multicolumn{1}{c}{ Immediate } & $5 \mathrm{~min}$ & $15 \mathrm{~min}$ & $30 \mathrm{~min}$ & Acid challenge \\
\hline OxaGel & $26.14 \pm 23.58 \mathrm{~A}$ & $23.03 \pm 11.96 \mathrm{Ba}$ & $17.14 \pm 9.69 \mathrm{Ba}$ & $13.46 \pm 7.72 \mathrm{Bb}$ & $11.03 \pm 6.39 \mathrm{Bb}$ & $17.63 \pm 8.56 \mathrm{~B}$ \\
DD-1 & $16.22 \pm 27.22 \mathrm{~A}$ & $21.76 \pm 9.95 \mathrm{Ba}$ & $16.09 \pm 8.02 \mathrm{Ba}$ & $12.09 \pm 6.13 \mathrm{Ba}$ & $9.09 \pm 4.59 \mathrm{Bb}$ & $16.71 \pm 6.53 \mathrm{~B}$ \\
DD-2 & $28.91 \pm 29.62 \mathrm{~A}$ & $29.71 \pm 12.75 \mathrm{Ba}$ & $22.69 \pm 10.22 \mathrm{Ba}$ & $17.01 \pm 8.8 \mathrm{Bb}$ & $13.78 \pm 7.01 \mathrm{Bb}$ & $22.61 \pm 12.54 \mathrm{~B}$ \\
Placebo & $31.22 \pm 20.61 \mathrm{~A}$ & $72.76 \pm 15.06 \mathrm{Aa}$ & $54.99 \pm 13.5 \mathrm{Ab}$ & $44.19 \pm 11.91 \mathrm{Ab}$ & $35.5 \pm 8.6 \mathrm{Ab}$ & $65.78 \pm 28.69 \mathrm{~A}$ \\
Water & $32.31 \pm 23.97 \mathrm{~A}$ & $74.00 \pm 15.35 \mathrm{Aa}$ & $61.96 \pm 16.06 \mathrm{Aa}$ & $48.03 \pm 14.56 \mathrm{Ab}$ & $37.69 \pm 13.35 \mathrm{Ab}$ & $86.57 \pm 52.19 \mathrm{~A}$
\end{tabular}

*Different lowercase letters in rows (intragroup comparisons were performed only regarding the time) and uppercase letters in columns indicate statistically significant differences at 5\% (Duncan's test). 
$(\mathrm{p}<0.05)$ were found between the three active desensitizing agents (OxaGel, DD-1 and DD-2) and the two controls (placebo and deionized water).

Table 1 shows the intragroup values of permeability over time. For Groups I and III (OxaGel and DD2 ), there was a decrease in permeability but this decline was statistically significant only at 15 and $30 \mathrm{~min}$ $(p<0.05)$. For Group II (DD-1), there was a significant decrease in dentin permeability at the 30-min interval $(p<0.05)$, although in this group, the values between the immediate period and 15-min interval were close to significance. In Group IV (placebo), statistically significant difference $(\mathrm{p}<0.05)$ was found among 5-, 15- and 30-min intervals. Permeability decrease was observed in Group V (deionized water) after 15 and $30 \mathrm{~min}$, although no active agent was employed in this group.

Figure 3 gives an overview of the materials' behavior under the tested conditions. In all groups, the values started near minimum permeability, reached maximum permeability $(100 \%)$ and decreased with time. This decline was outstanding for the active materials (OxaGel, DD-1 and DD-2), which showed resistance to acid challenge. For placebo agent and deionized water, there was also a decrease in permeability, even though this reduction did not result in resistance to acid challenge, with permeability returning to levels close to those of maximum permeability.

\section{DISCUSSION}

The device employed for assessment of dentin hydraulic conductance requires the use of a certain

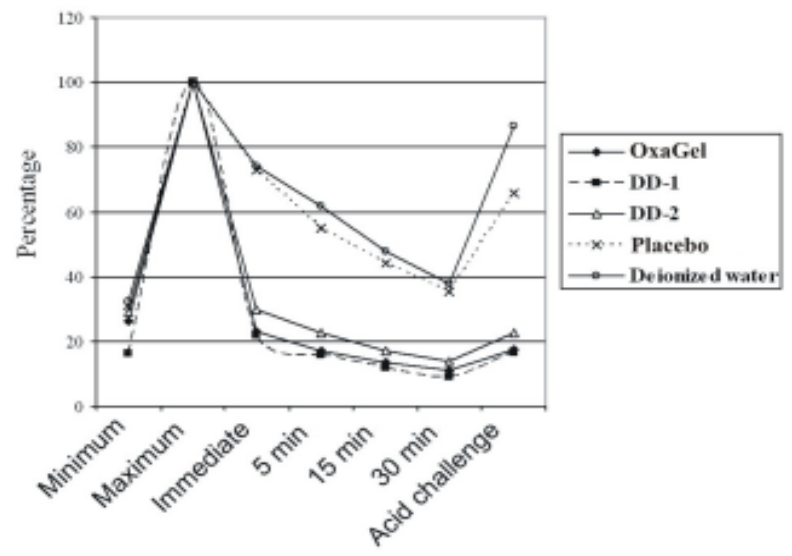

Figure 3. Behavior of the materials under the tested conditions. pressure for system movement and further measurement of dentin permeability. The liquid under pressure moves a microbubble situated in the micropipette during a certain period. The pressure applied in this study was $703.1 \mathrm{cmH}_{2} \mathrm{O}$ (10 psi) (7-9). Most studies (4-15) use higher pressures than the physiological pulpal pressure $\left( \pm 14 \mathrm{cmH}_{2} \mathrm{O}\right)$ for in vitro tests to allow greater reading speed. The experiments carried out with reduced pressure present as shortcomings reading delay and operator fatigue because the bubble moves very slowly. Therefore, the use of an automated fluid flow apparatus (Flodec, DeMarco Engineering, Geneva, Switzerland) has been suggested to allow faster measurement of displacement in the order of micrometers, which would be impossible to human eye perception $(16,17)$.

A previous study (10) reported that the variation of applied pressure and the time of pressure application may, somehow, interfere with the measurement of dentin hydraulic conductance. An increased intratubular resistance may occur under high pressures due to compression of internal tubules' content against tubule walls, reducing the values of hydraulic conductance. This decrease may be even greater when the filtration time increases from 10 to $180 \mathrm{~min}$. The use of physiological pressure does not affect the tubular content and no hydraulic conductance alteration occurs with time, leading to results closer to those of in vivo conditions.

The decrease of dentin permeability in vitro caused by potassium oxalate agents ranges from 95 to $98 \%(3,6)$. In the present study, there was an immediate dentin permeability decrease of $75 \%$ on average for all active materials.

One of the proposals of this study was to determine whether dentin hydraulic conductance measurement system interferes with the interpretation of the real action of desensitizing agents due to dentinal tubule occlusion. The first approach to the results (Table 1) shows that hydraulic conductance means for the active materials in the immediate period indicates an obstructive effectiveness very close to that provided by the smear layer. This permeability reduction is around $75 \%$ for all materials and smear layer. Table 1 also gives a view of spontaneous decrease of dentin permeability related to the studied time intervals. Therefore, it is clear that permeability decrease may possibly progress through the simple filtration of deionized water used in the system. This is probably associated with the effect of time and hydraulic pressure in the passive decrease of 
dentin permeability both for active and non-active agents. It is interesting to observe that this effect is more evident in the non-active rather than in the active agents because the active agents actually provide an immediate permeability reduction, great enough to conceal the effect of time and pressure on filtration. It is also important to consider that potassium oxalate formulations, such as these used in the present investigation, characteristically precipitates calcium oxalate crystals to some extension inside the dentinal tubules (18). These loosely arranged crystals might be further displaced toward tubule openings by the hydraulic pressure during the filtration procedure. The fluid pressure tends to force the crystals against each other to create a plug that actually reduces fluid filtration as time elapses. Obviously, the amount of pressure, as much as time, plays an important role in the process of tubule obstruction and in dentin filtration rates. On the other hand, because non-active agents do not provide immediate tubule mechanical obstruction, filtration decrease becomes more evident along time, probably due to the displacement of little particles that remained inside them. In fact, no statistically significant differences were observed between immediate and post-5-min filtration rates for active agents. Nevertheless, filtration rates showed significant differences between immediate and post- 15 and post-30 min intervals, except for DD-1, where no difference was found between the results of immediate and 15-min periods (Table 1).

Carboxymethylcellulose is an inert thickener used in OxaGel and DD-1 experimental agent formulations. These are respectively, $3 \%$ and $6 \%$ monohydrate potassium oxalate with neutral $\mathrm{pH}$, which is further adjusted to $\mathrm{pH} 2$. At the time the gel is obtained, the $\mathrm{pH}$ spontaneously raises to $\mathrm{pH} 4$. Theoretically, the reactivity of these formulations with dentin is regulated, in part, by the acid $\mathrm{pH}$, which in addition to the natural affinity of potassium with calcium and phosphate leads to crystal precipitation on the dentin and inside the dentinal tubules. The pattern of crystal precipitation and the ability to reduce dentin hypersensitivity have been reported in laboratory and clinical studies using these formulations $(19,20)$. On the other hand, the thickener employed for DD-2 experimental agent was carbopol. This thickener provides a potassium oxalate gel, which maintains the original $\mathrm{pH}$ of the solution around 2 . The lower $\mathrm{pH}$ is expected to improve the interaction between the gel and the dentin substrate, as discussed in other studies
$(19,20)$, although no difference in the hydraulic conductance of dentin discs treated with the 3 gels was recorded in the present investigation.

Two control groups (IV and V) were used in this study. In group IV distilled water plus carboxymethylcellulose gel was used, which was considered a nonactive or placebo agent. The rationale for the use of a placebo agent was the need to asses the actual effect of a gel without the active components on dentinal tubules obstruction and, consequently, on dentin permeability. Such a gel has frequently been applied as a placebo in previous clinical studies (19). Group V consisted of specimens without any previous treatment in which the deionized water flowed freely through dentin discs. Dentin hydraulic conductance was calculated after each time interval, as for the experimental groups. The aim of this procedure was to establish the dynamics of spontaneous flow of liquid in comparison with the experimental specimens into the split-chamber device.

The results on Table 1 pointed to two important evidences. First, there was no significant difference between the hydraulic conductance of dentin discs treated with the placebo gel and those treated with free flow in the system. Second, the hydraulic conductance showed a spontaneous decrease as time elapsed. The measurement of dentin hydraulic conductance for the specimens in group $\mathrm{V}$ showed an immediate reduction around $25 \%$ in contrast with the findings of Greenhill and Pashley (2) who used distilled water and obtained a hydraulic conductance reduction of only $0.2 \%$ on average. It is important to point out that the pressure used in that work was about 3 times smaller than that used in the present study. Camps et al. (10) reported that this decline of hydraulic conductance values with time may be due to the use of high pressures $\left(703.1 \mathrm{~cm} \mathrm{H}_{2} \mathrm{O}\right)$ or storage solution.

A reasonable explanation for such a spontaneous decrease of fluid filtration across the dentin discs is the present organic and inorganic remnants of within the tubules, which are not completely removed by acid etching. Under high fluid pressures, these debris may be displaced and occlude the tubules openings, as discussed earlier for crystals displacement in the experimental specimens.

The placebo agent presented a reduction of filtration similar to that of deionized water, not showing any additional potential for quantitative obstruction as the hydraulic conductance values for both groups did 
not differ significantly. The comparative analysis of filtration rates obtained with deionized water and the tested gels shows that the results must be interpreted cautiously because the obstructive effect of desensitizing agents may be the result of their reactivity with dentin and crystals precipitation and the obstructive potential effect of the measuring device itself.

Based on the results of the present study, it may be concluded that the system does interfere in the filtration results as a function of time because there was a trend towards reducing filtration values when the system freely flowed through the time intervals tested. The theoretical action of desensitizing agents must be interpreted as the difference between their effective reduction and the natural reduction provided by the system. Taking into account that the system produced an immediate reduction of $25 \%$ in the filtration, it may be inferred that every agent supposed to occlude the dentinal tubules will have a positive effect only if it surpasses the system's own obstructive effect.

\section{RESUMO}

O objetivo deste estudo in vitro foi avaliar a influência do tempo pós-aplicação de agentes anti-hiperestésicos comercial e experimentais na permeabilidade dentinária por meio da medição da condutibilidade hidráulica da dentina, utilizando-se o método de discos de dentina. Cinqüenta discos de dentina obtidos a partir de terceiros molares humanos recém extraídos foram divididos em 5 grupos $(\mathrm{n}=10)$, de acordo com o agente utilizado: Grupo I: OxaGel; Grupo II: agente experimental DD-1: Grupo III: agente experimental DD-2: Grupo IV: gel placebo; e Grupo V: água deionizada. Os agentes foram aplicados por 3 min e em seguida mediu-se a condutibilidade hidráulica da dentina nos tempos imediato, 5, 15, 30 min e após a aplicação de ácido. Os dados foram submetidos a análise estatística pelos testes de ANOVA a dois critérios e teste de Duncan com nível de significância de 5\%. Os Grupos I, II e III não diferiram significantemente uns dos outros em nenhum dos intervalos ( $p>0,05)$. Do mesmo modo, os Grupos IV e V foram similares estatisticamente $(p>0,05)$. Os agentes ativos reduziram significantemente a permeabilidade dentinária em comparação aos controles $(\mathrm{p}<0,05)$. A redução dos valores de permeabilidade em função do tempo apresentada pelo Grupo V, o qual não foi empregado agente anti-hiperestésico, faz com que a interpretação dos resultados dos demais grupos leve em consideração um arrefecimento natural da permeabilidade com o passar do tempo, proporcionado pelo dispositivo utilizado para a medição da condutibilidade hidráulica da dentina.

\section{REFERENCES}

1. Bissada NF. Symptomatology and clinical features of hypersensitive teeth. Arch Oral Biol 1994;39:31S-32S.
2. Walters PA. Dentinal hypersensitivity: a review. J Contemp Dent Pract 2005;6:107-117.

3. Greenhill JD, Pashley DH. The effects of desensitizing agents on the hydraulic conductance of human dentin in vitro. J Dent Res 1981;60:686-698.

4. Pashley DH. Dentin permeability, dentin sensitivity, and treatment through tubule occlusion. J Endod 1986;12:465-474.

5. Reeder OW, Walton RE, Livingston MJ, Pashley DH. Dentin permeability: determinants of hydraulic conductance. J Dent Res 1978;57:187-193.

6. Pashley DH, Galloway SE. The effects of oxalate treatment on the smear layer of ground surfaces of human dentine. Arch Oral Biol 1985;30:731-737.

7. Goodis HE, Marshall GW, White JM. The effects of storage after extraction of the teeth on human dentine permeability in vitro. Arch Oral Biol 1991;36:561-566.

8. Koutsi V, Noonan RG, Horner JA, Simpson MD, Matthews WG, Pashley DH. The effect of dentin depth on the permeability and ultrastructure of primary molars. Pediatr Dent 1994;16:29-35.

9. Simpson MD, Horner JA, Brewer PD, Eichmiller F, Pashley DH. Effects of aluminum oxalate/glycine pretreatment solutions on dentin permeability. Amer J Dent 1992;5:324328 .

10. Camps J, Giustiniani S, Dejau J, Franquin JC. Low versus high pressure for in vitro determination of hydraulic conductance of human dentine. Arch Oral Biol 1997;42:293-298.

11. Pashley DH, Linvgston MJ, Greenhill JD. Regional resistance to fluid flow in human dentine in vitro. Arch Oral Biol 1978;23:807-810.

12. Pashley DH, Nelson R, Kepler EE. The effects of plasma and salivary constituents on dentin permeability. J Dent Res 1982;61:978-981.

13. Pashley DH, Thompson SM, Stewart FP. Dentin permeability: effects of temperature on hydraulic conductance. J Dent Res 1983;62:956-959.

14. Pashley DH, O'meara JA, Kepler EE, Galloway SE, Thompson SM, Stewart FP. Dentin permeability- effects of desensitizing dentifrices in vitro. J Periodontol 1984;55:522525.

15. Prati C, Mongiorgi R, Ferrieri P. Effects of desensitizing toothpastes on dentine permeability. Arch Oral Biol 1994;39:144S.

16. Ciucchi B, Bouillaguet S, Holz J, Pashley DH. Dentinal fluid dynamics in human teeth in vivo. J Endod 1995;21:191-194.

17. Zhang Y, Agee K, Pashley DH, Pashley, EL. The effects of pain-free desensitizer on dentine permeability and tubule occlusion over time, in vitro. J Clin Periodontol 1998;25:884891.

18. Orchardson R, Gillam DG. Managing dentin hypersensitivity. J Am dent Assoc 2006;137:990-998 quiz 1028-1029.

19. Pereira JC, Martineli ACBF, Santiago SL. Treating hypersensitive dentin with three potassium oxalate-based gel formulations: a clinical study. J Appl Oral Sci (formerly Rev Fac Odontol Bauru) 2001;9:123-130.

20. Pereira JC, Segala AD, Gillam DG. Effect of desensitizing agents on the hydraulic conductance of human dentin subjected to different surface pre-treatments: an in vitro study. Dent Mater 2005;21:129-138.

Accepted April 11, 2005 